Part of Journal of Research of the National Bureau of Standards, Volume 32, January 1944

\title{
MEASUREMENT OF THE REFRACTIVE INDEX AND DIS- PERSION OF OPTICAL GLASS FOR CONTROL OF PRODUCT
}

\author{
By Helen L. Gurewitz and Leroy W. Tilton
}

\section{ABSTRACT}

Commercial critical-angle refractometers are inadequate for acceptance tests on optical glass for precision uses. To facilitate spectrometer determinations, coefficients ${ }^{1}$ have been devised which, together with a table of natural sines and slide-rule operations, permit the computation of refractive indices of glass with an accuracy of $\pm 3 \times 10^{-6}$ from minimum-deviation data taken on prisms having angles of $60^{\circ} \pm 30^{\prime}$.

The refractive index and dispersion of optical glass that is used for lenses and for other refractive purposes are the most important characteristics of such glass, and considerable attention should be given by the manufacturer to their appropriate measurement. Adequate measurements of dispersion are more difficult than those of refractive index as such. The value $\nu=\left(n_{D}-1\right) /\left(N_{F}-N_{c}\right)$, used for expressing the dispersion of optical glass, is often specified by purchasers with tolerances of two or three tenths of a unit. The critical factor in its determination is the partial dispersion $\left(N_{,}-N_{c}\right)$, which ranges from 0.00800 for borosilicate crown with $n_{D}=1.517$ and $\nu=64$, to 0.02100 for extra-dense flint with $n_{D}=1.671$ and $\nu=32$. It is evident that the difficulties exist chiefly for crown glass, where errors of \pm 0.000012 in measuring both $n_{\sigma}$ and $n_{F}$ can result in errors of \pm 0.2 in $\nu$ value.

Since it is obviously desirable that the errors of acceptance and rejection tests should be appreciably smaller than the tolerances specified for acceptance, and because the measurement of refractive index with errors of appreciably less than \pm 0.000012 is exceedingly difficult, there is a logical demand that the close tolerances sometimes specified for $\nu$ values, especially for crown glass, should be eased whenever it is possible to do so.

Following progress in the easing of acceptance tolerances, there is a tendency to abandon efforts to get optimum accuracy in index measurements. This tendency is unfortunate and surprising because tolerances for optical glass are usually comparable with, and sometimes smaller than, the limits within which a manufacturer controls his product, and under these conditions both seller and buyer should be interested in keeping the range of uncertainties in acceptance tests appreciably smaller than the tolerances specified for acceptance. Assuming only chance errors, and assuming definite acceptancefor

\footnotetext{
1 The computationsl process and the tables here described, with particular reference to glasses with indices in the range 1.509 to 1.532 , have been extended for glasses up to 1.677 in index. Copies of the full table of coefficients, $C$, have been duplicated for distribution upon request.
} 
rejection according to the results of relatively imprecise tests, the volume of acceptable product that is rejected will necessarily tend to exceed that of the unacceptable product that is delivered. This means great loss by the manufacturer when the specified tolerances approximate the limits within which he is able to control the major portion of the product. The interest of the purchaser increases as the specified tolerances become narrow in comparison with the degree of control, because the accepted glass will necessarily include much that lies outside the tolerances, and thus the accepted product will be much less homogeneous than is desired or supposed.

The importance of precision and accuracy in refractive index measurements for control of product is recognized by European manufacturers. According to the Jena glass catalog, spectrometer measurements are made by Zeiss for every melt with an accuracy of \pm 5 in the fifth decimal place for each refractive index and \pm 2 in the fifth decimal for each partial dispersion. This corresponds to \pm 0.15 in $v$ value for crown glass.

At the Chance-Parsons plant, a spectrometer is used to determine the dispersions listed in the catalog, and "routine measurements of refractive indices of meltings are made with a Pulfrich refractometer which has been standardized by reference prisms carefully measured on an accurate spectrometer." The "Pulfrich" refractometers used in England for such purposes are not the Pulfrich refractometers as made by Zeiss but improved models, specially built in England and calibrated at the National Physical Laboratory. Even so, it is admitted that the errors are \pm 3 in the fifth decimal place for the partial dispersions, which may correspond to \pm 0.23 in $\nu$.

At the National Bureau of Standards, with a Zeiss Pulfrich refractometer, it is found that errors in dispersion measurement are from 50 to 100 percent higher than those cited in the Chance-Parsons catalog for their Pulfrich refractometer measurements. There are no standard or "precision" refractometers that are commercially obtainable and sufficiently accurate to determine the $\nu$ values of light crown glass, in a manner satisfactory to either manufacturer or purchaser, when making acceptance tests where the $\nu$ values are specified to \pm 0.3 or \pm 0.5 . The highest accuracy attainable with the best of selected and tested precision refractometers approaches but certainly does not fully equal the accuracy that is desirable. The errors in such refractometric determinations result in an uncertainty of approximately \pm 0.5 in $\nu$ value for crown glass, and thus it could happen that almost all decisions reached by such procedures would be erroneous for crown glass.

Consequently, spectrometer measurements and the use of prisms are imperative for control of product in the manufacture of optical glass, if the constants of glass are to be known with the degree of accuracy that characterizes data commonly supplied with optical glass that is imported for high precision uses. Nevertheless, because of the time required for accurate spectrometer measurements, and also because the $\nu$ value of glass varies very little from melt to melt made with a given batch composition and manufacturing procedure, it may be advisable, especially during wartime, and for certain purposes, to rely to some extent on precision refractometer measurements for the values of the refractive indices themselves, and for the detection of gross errors in composition. 
Whenever critical-angle refractometers are employed for these purposes they should be used strictly as comparison instruments through continual use of representative specimens, including some from each type of glass, that have previously been standardized by use of a spectrometer. ${ }^{2}$ It is suggested that the $\nu$ value of a fine annealed sample from every fifth melt of crown glass of each type, all melts being made with a given batch composition and manufacturing procedure, and likewise from every tenth melt of flint glass, should be measured by means of an accurate spectrometer in order to obtain accurate information on $v$ values and to check the over-all accuracy of the refractometer procedures.

The time required for making prisms and for the spectrometer determinations can be safely reduced by slight easing of the tolerances on flatness of prism surfaces and by using a constant tube length for the collimator, ${ }^{3}$ also by approximate temperature control for all crown prisms. Moreover, the time required for the precise computation of refractive index to six or seven significant figures by the well-known formula

$$
n=\sin 0.5(A+D) / \sin 0.5 A,
$$

where $A$ is the refracting angle of the prism, and $D$ is the angle of minimum deviation, can be materially shortened and the chance of error reduced by use of a single-entry table of index as a function of modified or pseudo values of $2 D$. One table, made for prisms of exactly $60^{\circ}$, serves for all wavelengths, (visible spectrum) and for all prism angles in the neighborhood of $60^{\circ}$.

In making the table, the proper entries are readily computed as $n=2 \sin \left(30^{\circ}+0.5 D\right)$, which gives the index for a prism of exactly $60^{\circ}$. Thus for a tabulation at intervals of 1 minute of arc in $2 D$, which proves ample for precise work to six decimal places, one merely doubles the values read from a table of natural sines at intervals of 15 seconds of arc. Table 1 is an example of such a table. It includes the limited refractive-index range $n=1.509419$ to $n=1.531995$, especially useful with prisms of borosilicate glass.

The uniformity with which the sine changes in the neighborhood of $60^{\circ}$ and of $2 D$ (for glass prisms) permits the precise use of such a table for all prism angles within $60^{\circ} \pm 30^{\prime}$ by merely modifying, in each case, the actually observed $2 D_{A}$ by a quantity $\Delta 2 D$ that closely compensates for the particular existing $\triangle A=A-60^{\circ}$. In order to compute an auxiliary table for getting $\triangle 2 D$ for particular values of $\Delta A$, equation 1 is differentiated, and the desired relationship is expressible as

$$
\Delta 2 D=2[\sin 0.5 D \operatorname{cosec} 0.5 A \sec 0.5(A+D)] \Delta A,
$$

where for crown glass the quantity in brackets is so near 1 that it is convenient to rewrite equation 2 as

$$
\Delta 2 D=(1+C)(2 \Delta A)
$$

and tabulate in table 2 only the small coefficients, $C=(\Delta 2 D / 2 \Delta A)-1$. These can be used with a slide rule in evaluating for any crown-glass

2 L. W. Tilton, J. Opt. Soc. Am. 32, 371 (1942); J. Research NBS 30, 311-328 (1943) RP1535.

${ }^{3}$ L. W. Tilton, BS J. Research 11, 25-27 (1933) RP575. 
prism of $60^{\circ}+\Delta A$ the equivalent double deviation, $2 D_{60}$, for a prism of exactly $60^{\circ}$ in accord with the equation

$$
2 D_{60}=2 D_{\mathbf{\Delta}}-(2 \Delta A)-C(2 \Delta A) \text {. }
$$

With the values of $2 D_{60}$ thus computed, the refractive index of the prism that is being measured is found by linear interpolation in table 1.

In selecting a value of $C$ for use in equation 4 it is necessary to take a $C$ that is computed for the midrange of the particular $\triangle A$ and $\triangle 2 D$ in question. Accordingly, in making table 2, the $C$ values computed for $A_{c}=60^{\circ}+\Delta A / 2$ are tabulated under the observed values of $A=60^{\circ}+\Delta A$. Values of $C$ computed for $2 D_{c}=2 D_{A}-(1+C) \Delta A=$ $2 D_{60}+(1+C) \Delta A$ are tabulated on lines designated by values of $2 D$.

The computation of index can be quickly made with an accuracy of $\pm 3 \times 10^{-6}$, usually without logs, other tables, or a computing machine. The necessary steps are (1) find $C$ from table 2, and (2) find $-\Delta A=\left(60^{\circ}-A\right)$. Then (3) mentally double $-\Delta A$ and (4), usually with a slide rule, form product $-C(2 \Delta A)$ in order (5) to add the terms $-2 \Delta A$ and $-C(2 \Delta A)$ to $2 D_{A}$ and thus obtain $2 D_{60}$ with which (6) to enter table 1 for $n$. Two examples of the use of these tables are appended, and for one of them the corresponding solution by logarithms is given.

$$
\text { TABLE 1.-Indices of refraction, } 1.5094 \text { to } 1.5320 \text { for } 60^{\circ} \text { prism }
$$

[For other prisms, $A=60^{\circ} \pm 30^{\prime}$, find $2 D=0 D_{\Delta}-2 \Delta A-C(2 \Delta A)$. See table 2. Read initial digits in 0 column on same line with tabulated values unless asterisk refers to initial digits on next line below.]

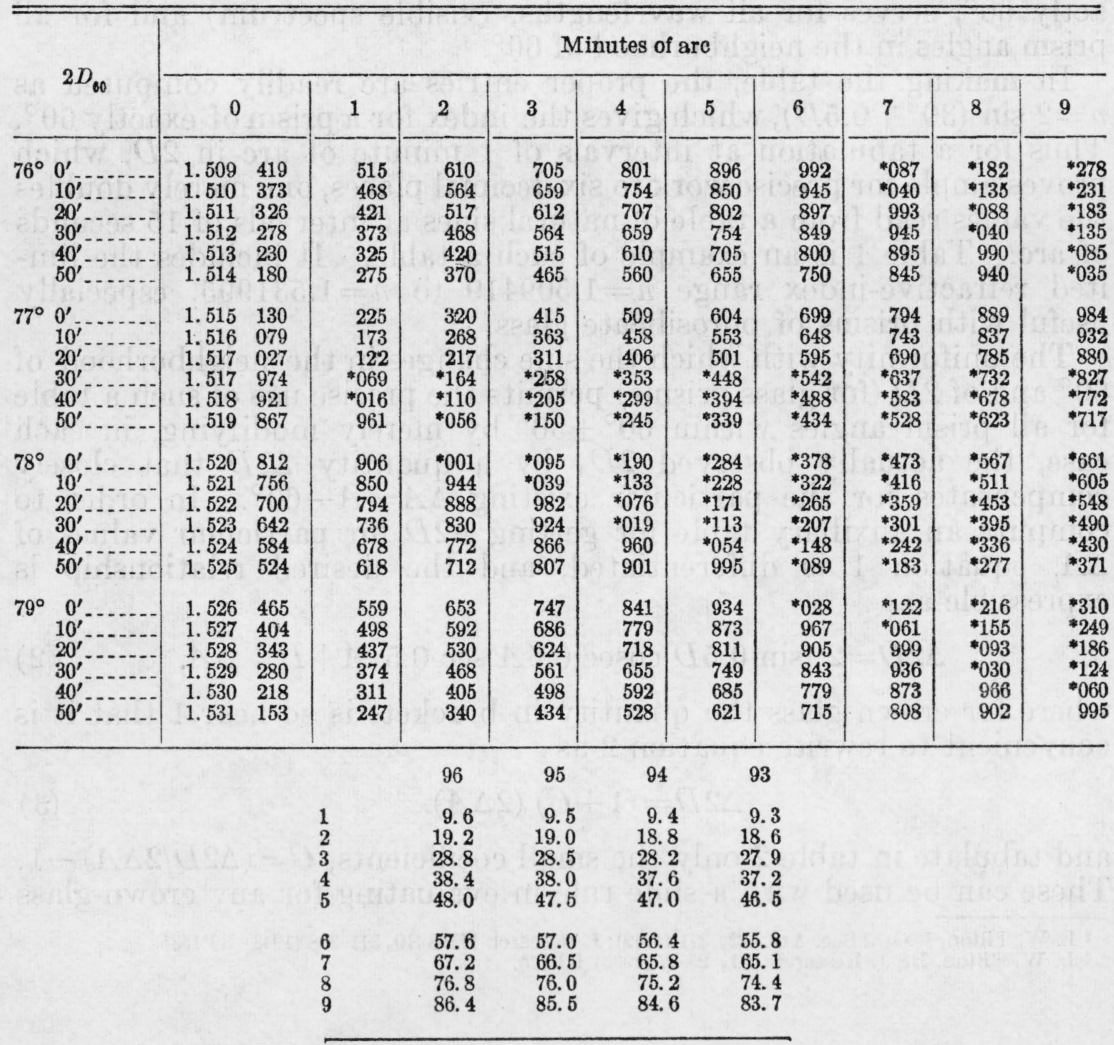


TABLE 2.-Coefficients for use with table 1 when $A$ differs from $60^{\circ}$

[Divide values listed below by 100 to get $C=(\Delta 2 D / 2 \Delta A)-1$.]

\begin{tabular}{|c|c|c|c|c|c|c|c|}
\hline \multirow{2}{*}{ Observed $2 D$} & \multicolumn{7}{|c|}{ Observed values of $A$} \\
\hline & $59^{\circ} 30^{\prime}$ & $59^{\circ} 40^{\prime}$ & $59^{\circ} 50^{\prime}$ & $60^{\circ} 00^{\prime}$ & $60^{\circ} 10^{\prime}$ & $60^{\circ} 20^{\prime}$ & $60^{\circ} 30^{\prime}$ \\
\hline $\begin{array}{l}76^{\circ} 00^{\prime} \\
10 \\
20 \\
30 \\
50\end{array}$ & $\begin{array}{r}+0.25 \\
.55 \\
.85 \\
1.15 \\
1.45 \\
1.74\end{array}$ & $\begin{array}{r}-0.08 \\
+.22 \\
.51 \\
.81 \\
1.10 \\
1.40\end{array}$ & $\begin{array}{r}-0.41 \\
-.11 \\
+.17 \\
.47 \\
.76 \\
1.06\end{array}$ & $\begin{array}{r}-0.75 \\
-.45 \\
-.16 \\
+.13 \\
.42 \\
.72\end{array}$ & $\begin{array}{r}-1.08 \\
-0.79 \\
-.50 \\
-.21 \\
+.08 \\
.37\end{array}$ & $\begin{array}{r}-1.41 \\
-1.12 \\
-0.84 \\
-.55 \\
-.26 \\
+.03\end{array}$ & $\begin{array}{r}-1.74 \\
-1.46 \\
-1.18 \\
-0.89 \\
-.60 \\
-.31\end{array}$ \\
\hline $\begin{array}{r}77^{\circ} 00^{\prime} \\
10 \\
20 \\
30 \\
40 \\
50\end{array}$ & $\begin{array}{l}2.03 \\
2.33 \\
2.63 \\
2.94 \\
3.24 \\
3.54\end{array}$ & $\begin{array}{l}1.69 \\
1.99 \\
2.29 \\
2.60 \\
2.90 \\
3.20\end{array}$ & $\begin{array}{l}1.35 \\
1.65 \\
1.95 \\
2.25 \\
2.55 \\
2.85\end{array}$ & $\begin{array}{l}\text { 1. } 01 \\
\text { 1. } 31 \\
\text { 1. } 60 \\
\text { 1. } 90 \\
\text { 2. } 20 \\
\text { 2. } 50\end{array}$ & $\begin{array}{r}0.66 \\
.96 \\
1.26 \\
1.55 \\
1.85 \\
2.15\end{array}$ & $\begin{array}{r}0.32 \\
.62 \\
.92 \\
1.21 \\
1.51 \\
1.81\end{array}$ & $\begin{array}{r}-0.02 \\
+.28 \\
.58 \\
.87 \\
1.17 \\
1.47\end{array}$ \\
\hline $\begin{array}{l}78^{\circ} 00^{\prime} \\
10 \\
20 \\
30 \\
50\end{array}$ & $\begin{array}{l}3.84 \\
4.14 \\
4.45 \\
4.76 \\
5.07 \\
5.37\end{array}$ & $\begin{array}{l}\text { 3. } 50 \\
3.80 \\
\text { 4. } 10 \\
\text { 4. } 40 \\
\text { 4. } 71 \\
\text { 5. } 02\end{array}$ & $\begin{array}{l}\text { 3. } 15 \\
3.45 \\
\text { 3. } 75 \\
\text { 4. } 05 \\
\text { 4. } 35 \\
\text { 4. } 66\end{array}$ & $\begin{array}{l}2.80 \\
3.10 \\
3.40 \\
3.70 \\
4.00 \\
4.30\end{array}$ & $\begin{array}{l}2.45 \\
2.74 \\
3.04 \\
\text { 3. } 35 \\
3.65 \\
3.94\end{array}$ & $\begin{array}{l}2.11 \\
2.40 \\
2.70 \\
3.00 \\
3.30 \\
3.59\end{array}$ & $\begin{array}{l}1.76 \\
2.06 \\
2.36 \\
2.65 \\
2.95 \\
3.24\end{array}$ \\
\hline $79^{\circ} 00^{\prime}$ & $\begin{array}{l}5.68 \\
5.99 \\
6.30 \\
6.61 \\
6.91 \\
7.21\end{array}$ & $\begin{array}{l}5.32 \\
5.62 \\
5.94 \\
6.24 \\
6.54 \\
6.85\end{array}$ & $\begin{array}{l}4.96 \\
5.26 \\
5.57 \\
5.87 \\
6.17 \\
6.48\end{array}$ & $\begin{array}{l}4.60 \\
4.90 \\
5.20 \\
5.50 \\
5.80 \\
6.11\end{array}$ & $\begin{array}{l}4.24 \\
4.54 \\
4.85 \\
5.15 \\
5.45 \\
5.75\end{array}$ & $\begin{array}{l}3.89 \\
4.19 \\
4.49 \\
4.79 \\
5.09 \\
5.39\end{array}$ & $\begin{array}{l}3.54 \\
3.84 \\
4.13 \\
4.43 \\
4.73 \\
5.03\end{array}$ \\
\hline
\end{tabular}

COMPUTATION OF REFRACTIVE INDEX, $n$

Two examples by use of tables 1 and 2 :

\begin{tabular}{|c|c|c|}
\hline Remarks & Example $1\left(A<60^{\circ}\right)$ & Example $2\left(A>60^{\circ}\right)$ \\
\hline $\begin{array}{l}\text { Observed } A \\
\text { Observed } 2 D \\
C(\text { table } 2) \\
-\Delta A=\left(60^{\circ}-A\right) \\
-(2 \Delta A) \\
-C(2 \Delta A)\end{array}$ & $\begin{array}{rr} & 59^{\circ} 45.38^{\prime} \\
& 77^{\circ} 47.59^{\prime} \\
0.0295 & \\
14.62^{\prime} & \\
(.0295 \times 29.2)= & 29.24 \\
& 0.86\end{array}$ & $\begin{array}{rr} & 60^{\circ} 17.04^{\prime} \\
0.0136 & 77^{\circ} 31.56^{\prime} \\
-17.04^{\prime} & \\
-(.0136 \times 34.1)= & -34.08 \\
- & -0.46\end{array}$ \\
\hline $\begin{array}{l}2 D_{60} \\
n(\text { table } 1)\end{array}$ & $78^{\circ} 17.69^{\prime}$ & $76^{\circ} 57.02^{\prime}$ \\
\hline
\end{tabular}


44 Journal of Research of the National Bureau of Standards

\section{COMPUTATION OF REFRACTIVE INDEX, $n$}

One example by use of logarithms:

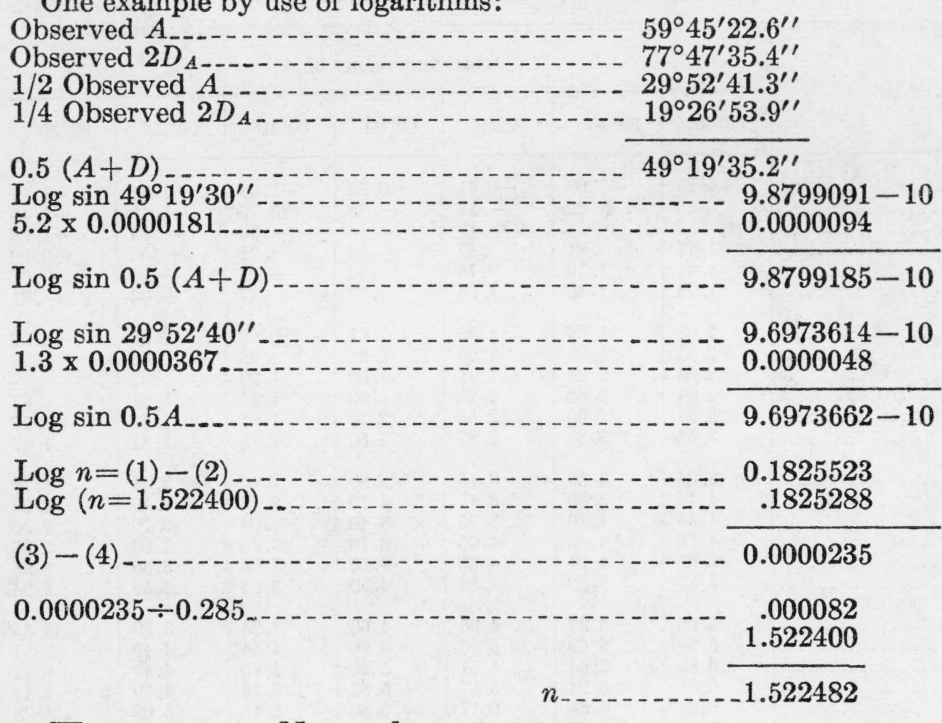

Washington, November 19, 1943. 
NATIONAL BUREAU OF STANDARDS, WASHINGTON 25, D. C.

Send me the Mathematical Tables marked $\mathrm{X}$ below. I enclose remittance ${ }^{1}$ to cover the cost.

\begin{tabular}{|c|c|c|c|c|}
\hline Mark X & Title of publication & $\begin{array}{l}\text { United States and } \\
\text { its possessions, } \\
\text { and countries ex- } \\
\text { tending franking } \\
\text { privilege } \\
\end{array}$ & $\begin{array}{l}\text { Other } \\
\text { countries }\end{array}$ & Amount enclosec \\
\hline (1) & 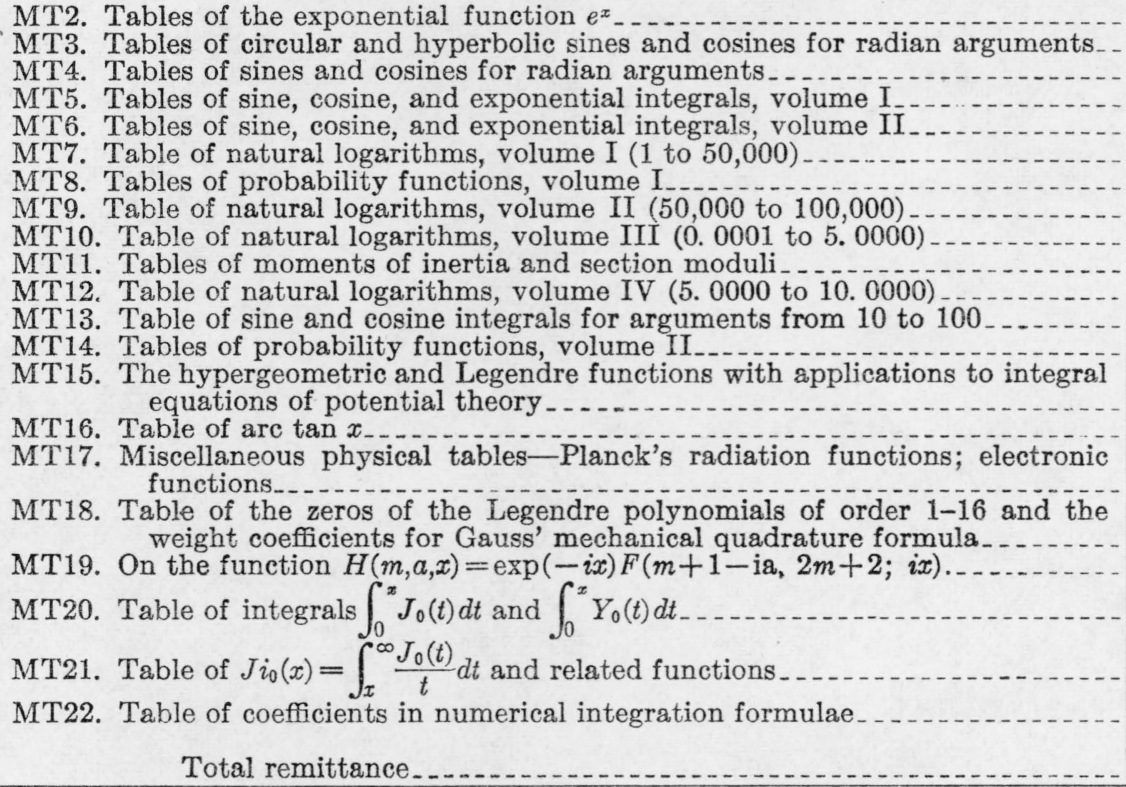 & $\begin{array}{r}\$ 2.00 \\
2.00 \\
2.00 \\
2.00 \\
2.00 \\
2.00 \\
2.00 \\
2.00 \\
2.00 \\
2.00 \\
2.00 \\
2.00 \\
2.00 \\
2.00 \\
2.00 \\
1.50 \\
\\
.25 \\
.25 \\
.25 \\
.25 \\
.25\end{array}$ & $\begin{array}{r}\$ 2.50 \\
2.50 \\
2.50 \\
2.50 \\
2.50 \\
2.50 \\
2.50 \\
2.50 \\
2.50 \\
2.50 \\
2.50 \\
2.50 \\
2.50 \\
2.50 \\
2.50 \\
1.75 \\
\\
.30 \\
.30 \\
.30 \\
\\
.30 \\
.30\end{array}$ & - \\
\hline
\end{tabular}

${ }^{1}$ Remittance should be in form of post-office money order, or check, and made payable to the order of the "National Bureau of Standards" in United States currency.

Send to

Number and Street

City and State 


\section{MATHEMATICAL TABLES}

Attention is invited to a series of publications prepared by the Project for the Computation of Mathematical Tables conducted by the Federal Works Agency, Work Projects Administration for the City of New York, under the sponsorship of the National Bureau of Standards. The tables which have been made available through the National Bureau of Standards are listed below.

There is included in this list a publication on the hypergeometric and Legendre functions (MT15), prepared by the Bureau.

MT1. Table or thb First Ten Power8 of the Integrrs From 1 to 1000:

(1938) VIII + 80 pages; heavy paper cover. Out of print.

MT2. Tables of the Exponential Function $e^{x}$ :

The ranges and intervals of the argument and the number of decimal places in the entries are given below:

$\begin{array}{ccc}\text { Range of } x & \text { Interval of } x & \text { Decimals given } \\ -2.5000 \text { to } 1.0000 & 0.0001 & 18 \\ 1.0000 \text { to } 2.5000 & .0001 & 15 \\ 2.500 \text { to } 5.000 & .001 & 15 \\ 5.00 \text { to } 10.00 & .01 & 12\end{array}$

(1939) XV+535 pages; bound in buckram, $\$ 2.00$.

MT3. Tables of Circular and Hyperbolic Sines and Cosings for Radian Arguments:

Contains 9 decimal place values of $\sin x, \cos x, \sinh x$ and $\cosh x$ for $x$ (in radians) ranging from 0 to 2 at intervals of 0.0001 .

(1939) XVII + 405 pages; bound in buckram, $\$ 2.00$.

MT4. Tables of Sines and Cosines for Radian Arguments:

Contains 8 decimal place values of sines and cosines for radian arguments ranging from 0 to 25 at intervals of 0.001 .

(1940) XXIX + 275 pages; bound in buckram, $\$ 2.00$.

MT5. Tables of Sine, Cosine, and Exponential Intrgrals, Volumb I:

Values of these functions to 9 places of decimals from 0 to 2 at intervals of 0.0001 .

(1940) XXVI+444 pages; bound in buckram, $\$ 2.00$.

MT6. Tables of Sine, Cosine, and Exponential Integrals, Volumb II:

Values of these functions to 9,10 , or 11 significant figures from 0 to 10 at intervals of 0.001 , with auxiliary tables.

(1940) XXXVII + 225 pages; bound in buckram, $\$ 2.00$.

MT7. Tablb of Natural Logarithms, Volume I:

Logarithms of the integers from 1 to 50,000 to 16 places of decimals.

(1941) XVIII + 501 pages; bound in buckram, $\$ 2.00$.

MT8. Tables or Probability Functions, Volumb I:

Values of these functions to 15 places of decimals from 0 to 1 at intervals of 0.0001 and from 1 to 5.6 at intervals of 0.001 .

(1941) XXVIII + 302 pages; bound in buckram, $\$ 2.00$.

MT9. Table of Naturaz Logarthim, Volume II:

Logarithms of the integers from 50,000 to 100,000 to 16 places of decimals.

(1941) XVIII+ 501 pages; bound in buckram, $\$ 2.00$.

MT10. Table of Natural Logarithms, Volumb III:

Logarithms of the decimal numbers from 0.0001 to 5.0000 , to 16 places of decimals.

(1941) XVIII + 501 pages; bound in buckram, $\$ 2.00$.

MT11. Tables of the Moments of Inertia and Section Moduli or Ordinary Angleg Chan. nels, and Bulb Angles with Certain Plate Combinations:

(1941) XIII+197 pages; bound in green cloth. $\$ 2.00$.

【Continued on p. 4 of cover》 
MT12. Table of Natural Logarithm, Volume IV:

Logarithms of the decimal numbers from 5.0000 to 10.0000 , to 16 places of decimals.

(1941) XXII + 506 pages; bound in buckram, $\$ 2.00$.

MT13. Table of Sine and Cosine Intrgrals for Arguments From 10 to 100:

(1942) XXXII +185 pages, bound in buckram, $\$ 2.00$.

MT14. Tables of Probability Functions, Volume II:

Values of these functions to 15 places of decimals from 0 to 1 at intervals of 0.0001 and from

1 to 7.8 at intervals of 0.001 .

(1942) XXI + 344 pages; bound in buckram, $\$ 2.00$.

MT15. The hypergeometric and Legendre functions with applications to integral equations of potential theory. By Chester Snow, National Bureau of Standards. Reproduced from origina! handwritten manuscript.

(1942) VII +319 pages; bound in heavy paper cover. $\$ 2.00$.

MT16. TaBle of ARc TAN $x$ :

Table of inverse tangents for positive values of the angle in radians. Second central differences are included for all entries.

$$
x=\llbracket 0(.001) 7(.01) 50(.1) 300(1) 2,000(10) 10,000 ; 12 D \rrbracket
$$

(1942) XXV+169 pages; bound in buckram, $\$ 2.00$.

MT17. Miscellaneous Physical Tables:

Planck's radiation functions (Originally published in the Journal of the Optical Society of America, February 1940); and

Electronic functions.

(1941) VII + 58 pages; bound in buckram, $\$ 1.50$.

MT18. Table of the Zeros of the Legendre Polynomials of Order 1-16 and the Weight Coefficients for Gauss' Mechanical Quadrature Formula.

(Reprinted from Bul. Amer. Mathematical Society, October 1942.)

5 pages with cover. 25 cents.

MT19. On the Function $H(m, a, x)=\exp (-i x) F(m+1-i a, 2 m+2 ; i x)$; with table of the confluent hypergeometric function and its first derivative.

(Reprinted from Journal of Mathematics and Physics," December 1942.) 20 pages, with cover. 25 cents.

MT20. Table of Integrals $\int_{0}^{x} J_{0}(t) d t$ and $\int_{0}^{x} \Upsilon_{0}(t) d t:$

Values of the two integrals are given for $x=O(.01) 10$ to 10 decimal places. (Reprinted from Journal of Mathematics and Physics, May 1943.) 12 pages, with cover, 25 cents.

MT21. Table of $J i_{\theta}(x)=\int_{x}^{\infty} \frac{J_{0}(t)}{t} d t$ and Related Functions:

Table I: $J i_{0}(x)$ to 10 decimal places and $F(x)=J i_{0}(x)+\log _{0} 1 / 2 x$ to 12 decimal places for $x=0(.1) 3$ with even central differences of $F(x)$.

Table II: $J i_{0}(x)$ to 10 decimal places, for $x=3(.1) 10(1) 22$ with even central differences up to $x=100$.

Table III: "Reduced" derivatives of $F(x)$ for $x=10(1) 21$ and $n=0(1) 13$, to 12 decimal places.

(Reprinted from Journal of Mathematics and Physics, June 1943.) 7 pages, with cover, 25 cents.

MT22. Table of Coefficients in Numerical Integration Formulae:

The values of $B^{(n)}{ }_{n}(1) / n !$ and $B^{(n)} n / n$ ! where $B^{(n)}{ }_{n}$ (1) denotes the $n$th Bernoulli polynomial of the $n$th order for $x=1$ and $B^{(n)}$ denotes the $n^{\text {th }}$ Bernoulli number of the $n^{\text {th }}$ order, were com. puted for $n=1,2, \ldots 20$. The quantities $B^{(n)}{ }_{n}(1) / n !$ are required in the Laplace formula of numerical integration employing forward differences, as well as in the Gregory formula. The quantities $B^{(n)} n / n$ ! are used in the Laplace formula employing backward differences.

(Reprinted from Journal of Mathematics and Physics, June 1943.) 2 pages, with cover, 25 cents.

Payment is required in advance. Make remittance payable to the "National Bureau of Standards," and send with order, using the blank form facing page 3 of the cover.

A mailing list is maintained for those who desire to receive announcements regarding new tables as they become available. 